\title{
UM GESTO DE LEITURA SOBRE O ESTÁGIO SUPERVISIONADO OBRIGATÓRIO EM LÍNGUA PORTUGUESA
}

Ieda Márcia Donati Linck é doutoranda em Linguística pelo PPGL/UFSM, sob orientação da professora Dra. Amanda Eloina Scherer. Mestre em Estudos Linguísticos pela UPF. Mestre em Educação pela Uninorte. Docente da Universidade de Cruz Alta/RS. Bolsista Capes/Parfor. E-mail: imdlinck@ gmail.com

Fabiane da Silva Verissimo é mestre em Comunicação Midiática pela UFSM. Bacharel em Publicidade e Propaganda pela Unicruz. E-mail: fabi@comnet.com.br

Zélia Maria Viana Paim é pós-doutoranda, bolsista do Programa Nacional de Pós-Doutorado Institucional (PNPD)/Coordenação de Aperfeiçoamento de Pessoal de Nível Superior (CAPES)/Programa de Pós-Graduação em Letras (PPGL)/Universidade Federal de Santa Maria (UFSM). E-mail: zéliamvp@gmail.com

\section{Resumo}

Pela Análise do Discurso de linha pecheutiana tomamos para estudo o nome da disciplina "Estágio Supervisionado em Língua Portuguesa", buscando compreender os deslocamentos de sentido que isso provoca na relação que estabelece como discurso institucional, considerando que "supervisionar" - presente, em uma de suas formas nominais, no referido nome - pode ser deslocado para sentidos diversos, mas não para todos, tampouco para qualquer um.

\begin{abstract}
Through pecheutiana line Discourse Analysis, for study we take the name of the discipline "Supervised Internship in Portuguese Language", trying to understand the displacements of sense that it causes in relation to establish as institutional discourse, considering that "supervise" - present, in one of their nominal forms, in referred name - can be moved to different senses, but not for everyone, neither for anyone.
\end{abstract}

\section{Introdução}

A imagem constitutiva do sujeito professor de língua portuguesa tem sido objeto de nosso percurso de reflexão, em que buscamos compreender o modo como ele é discursivizado nos documentos oficiais que dizem respeito ao processo de disciplinarização do Estágio Supervisionado Obrigatório nos Cursos de Letras no Brasil, a partir de $1960^{1}$, considerando que esses estão inseridos em "um domínio vasto e ainda pouco explorado para a história das disciplinas" (SCHERER, 2005, p. 14).

Temos nossa base teórica na Análise do Discurso (AD) de linha pecheutiana como vem sendo desenvolvida no Brasil e sua ligação com a História das Ideias Linguísticas (HIL), onde nos ancoramos para analisar as relações que se estabelecem entre a língua, o sujeito e a história na política de escolarização, ou seja, os efeitos da história, da ideologia e do político nas práticas linguísticas e pedagógicas que norteiam a ação e constituição da imagem do professor.

Nesse texto, tomamos para análise o nome da disciplina "Estágio Supervisionado em Língua Portuguesa", buscando compreender os deslocamentos de sentido que isso provoca na relação que estabelece como discurso institucional, considerando que "supervisionar" - presente, em uma de suas formas nominais, no referido nome - pode ser deslocado para sentidos diversos, mas não para todos, indiferentemente, tampouco para qualquer um, isso porque um nome não é uma palavra aleatória ou qualquer palavra. $\mathrm{O}$ nome sempre quer dizer alguma coisa e sua relação

\footnotetext{
${ }^{1}$ A escolha do recorte temporal tem relação com o período de democratização do ensino no país, que coincide com a implantação do estágio obrigatório no ensino superior no Brasil.
} 
com a significação é complexa, pois os nomes e seus (então possíveis) significados sempre geram sentidos outros.

Ao buscar as acepções dos termos que compõem o nome da referida disciplina, detemo-nos na palavra "supervisionado", a qual, segundo o Dicionário Larousse (2000), em seu infinitivo, apresenta, para supervisionar: "v.t. (conj. 4). Supervisar" (p.1061); se seguirmos nessa lógica, para a definição de supervisar, além de dirigir e orientar, apresenta-se "inspecionar", um verbo transitivo definido como: "1. Vistoriar, examinar para controlar. 2. Examinar com grande atenção. 3. Vigiar, revistar. 4. Proceder a um controle para verificar a destinação, a carga, estado sanitário etc. de um navio ou avião" (2000, p.636).

As definições obtidas no dicionário instigam-nos a pensar sobre o nome "supervisionado", pelo que ele pode trazer junto: uma naturalidade em pensar o estágio como um período de prática do que foi aprendido na teoria. $\mathrm{O}$ controle, nesse caso, se daria para confirmar se a estrutura trabalhada na universidade está, de fato, sendo reproduzida à risca, sem deslizamentos, na escola, pelo futuro professor, sob a vigilância in loco de quem já sabe sobre quem deve aprender a fazer algo.

Diante dessas considerações, vale pensar o porquê do termo "supervisionado". Quem assim a nomeou? Para Platão (2001, p.110-111), a nomeação é uma função da linguagem, como um instrumento, seguindo o seu próprio exemplo, um furador que utilizamos para perfurar, ou uma lançadeira que usamos para tecer. Assim também o nome é o que usamos para nomear. Nomear é designar alguma coisa e isso, segundo o filósofo, significa dar informação da coisa designada aos outros. Ou seja, é distinguir uma coisa entre outras conforme suas constituições. Se há um nome é porque há o que é nomeado.

Assim como Guimarães (2003, p. 53) fala de designação de espaços da cidade, falamos em designação de espaços acadêmicos, igualmente identificados entre as disciplinas que formam o conjunto de elementos sociais que as constituem nesse espaço, cujos sentidos estão ali constituídos. Para Guimarães (2003, p. 54), "a nomeação é o funcionamento semântico pelo qual algo recebe um nome. Por exemplo, se numa situação dada e adequada o dono de um barco escreve sobre ele o nome Brisa, ele lhe está dando este nome, está nomeando o barco".

Os efeitos de sentido que mobilizam o uso do termo "Supervisão" são diversos, mas para pensá-los precisamos entender o processo sócio-histórico de constituição dos sentidos. Isso porque, em se tratando de uma prática de ensino, é o imaginário de língua constituído que estabelece suas finalidades pedagógicas, bem como que move a constituição do ensino de língua escolarizada, na relação estabelecida entre o par: professor/aluno.

Fizemos um recorte que é temporal, mas em relação à temporalidade, vale colocar que "quando falamos de origem, não se trata evidentemente de um acontecimento, mas de um processo que podemos delimitar num intervalo temporal aberto, às vezes consideravelmente longo" (AUROUX, 1992, p. 21).

\footnotetext{
${ }^{2} \mathrm{O}$ recorte feito para esta discussão refere-se apenas ao Estágio Supervisionado Obrigatório em Língua Portuguesa, prática presente nos demais cursos de Licenciatura na atualidade.
} 


\section{1) Considerações teóricas}

A língua, como um saber escolarizado, numa perspectiva de unidade, é um espaço de reprodução de conhecimento, em relações dissimuladas de transmissão de poder, desde a sua institucionalização. Isso resulta da "relação constitutiva entre a produção-transmissão do conhecimento linguístico e uma exterioridade histórico-social datada que se materializa em políticas de língua, em metodologias e tecnologias de ensino" (SILVA, 1998, p. 43).

A implantação de qualquer disciplina no ensino superior, dentre elas o Estágio Supervisionado Obrigatório em Língua Portuguesa ${ }^{3}$, passa pelo funcionamento da política de escolarização da língua nacional que se constrói no interior das políticas públicas de educação, consideradas como políticas sociais do Estado, enquanto direito social e democrático (SILVA, 1998). Ou seja, a relação estabelecida entre a língua de uma nação e os sujeitos envolve questões políticas, históricas e ideológicas.

A nomeação de uma disciplina faz parte do processo de colonização linguística de um país, contribuindo para a constituição de um imaginário de língua, bem como do sujeito que essa relação constitui pela designação, considerada por Guimarães (2003, p. 54) como "a significação de um nome enquanto sua relação com outros nomes e com o mundo recortado historicamente pelo nome. A designação não é algo abstrato, mas linguístico e histórico". Ou seja, estabelece uma relação da língua na forma simbólica, com o real, ao real, expondo-se a ele.

Pensar sobre o nome e no que ele significa, remete a alguma forma de designação, como se um nome servisse para designar as coisas, pessoas, lugares, disciplinas, enfim, como se ele servisse para especificar algo que é nomeado. Diante disso, especificar ou designar algo quer dizer: separar alguma coisa para lhe dar destaque, para lhe dirigir uma "certa" exclusividade de tratamento, ou seja, para se referir a algo sem recorrer a alguma interferência que um nome pode ter em outro.

Nesse sentido, para compreender o processo de construção e os sentidos das instituições e dos sujeitos que a praticam, desde a década de 1980, o Programa de História das Ideias Linguísticas vem estudando a constituição dos sujeitos, da sociedade e da história. Ele formou-se a partir de conhecimento produzido em projetos desenvolvidos na área. Dentre estes, tem papel particular "Discurso, Significação, Brasilidade", projeto coletivo desenvolvido na Unicamp com o grupo de análise de discurso coordenado por Orlandi, para quem, "é preciso pensar a relação Língua/Nação/Estado e o cidadão que essa relação constitui” (2001, p. 9).

Como antecipado em Pêcheux (2009, p. 49), essa relação remete ao préconstruído, passível de análise no nome supervisionado, que, ao designar, naturaliza algo já posto, pensado e autorizado por um já dito sobre o imaginário social da relação estabelecida entre quem ensina e quem aprende, quem pensa e quem executa. Não há,

\footnotetext{
3 Bianchi (2002, p.68) define o estágio como “Acompanhar, fisicamente se possível, tornando essa atividade incomum, produtiva é tarefa do professor, que visualiza com o aluno situações de trabalho passíveis de orientação".
} 
então, como separar a questão da nomeação com a concepção de língua do universo acadêmico, já que o imaginário de língua constituído legitima a designação dada à prática de estágio; se ela for pensada como um sistema perfeito, uma estrutura acabada, fora do sujeito, que deve ser guardada, o nome dado à disciplina terá de ser supervisionado mesmo. Pela regularidade instalada, dificilmente, o sujeito se pergunta por que esse nome e não outro.

A partir da perspectiva em que se filia este trabalho, a $\mathrm{AD}$, entendemos que esse "já dito" insere-se em uma rede de filiações determinadas historicamente, articulado ao complexo de formações ideológicas, sendo que alguma coisa fala antes, em outro lugar, independentemente. $\mathrm{O}$ interdiscurso foi concebido inicialmente por Pêcheux (1995, p. 162) como o "todo complexo como dominante' das formações discursivas (...) submetido à lei de desigualdade-contradição-subordinação" que caracteriza a Formação Ideológica (FI). O interdiscurso constitui-se como um lugar onde todos os sentidos estão, mas só vão significar quando convocados por uma determinada Formação Discursiva (FD). Pêcheux denomina "formação discursiva aquilo que, numa formação ideológica dada, isto é, a partir de uma posição dada numa conjuntura dada, determinada pelo estado de luta de classes, determina o que pode $e$ deve ser dito" (1995, p. 160).

A língua que o aluno em fase de estágio deverá ensinar é aquela sistematizada na escola, sendo esta uma instituição de uma sociedade dada, gerida pelo Estado, marcada por realidades complexas e contraditórias, também caracterizada por colocar em jogo práticas, teorias, metodologias e tecnologias que são datadas historicamente, que se aliam/confrontam aos interesses e necessidades materiais dos diferentes grupos sociais. Assim sendo, na imagem desse sujeito professor estão pautadas todas as práticas referentes à escolarização da língua nacional: é preciso supervisionar/controlar o sujeito que está sendo preparado para guardar/ensinar a língua que o representa. De onde vem isso? Indursky (2003, p. 104) ressalta que o efeito de memória, que é fortemente lacunar, possibilita que os sentidos "derivem, deslizem, se transformem e ressignifiquem".

\section{2) Considerações sócio-históricas}

Nem sempre o estágio supervisionado foi obrigatório, inclusive muitos gramáticos, como por exemplo, Joaquim Mattoso Câmara ${ }^{4}$, não cursaram a faculdade de Letras e nem passaram por qualquer espécie de prática de estágio. Com base na pesquisa que estamos desenvolvendo, o Estágio no Ensino Superior é citado na Lei 40.24/61, primeira Lei de Diretrizes e Bases da Educação, tornando-se obrigatório após a sua regulamentação, que coincide com a democratização do ensino no país e, mais tarde, com institucionalização da Linguística como disciplina obrigatória no ensino

\footnotetext{
${ }^{4}$ Membro fundador da Academia Brasileira de Filologia. Sob sua orientação, foi fundada, em 1969, a Associação Brasileira de Linguística, da qual participou na sua primeira gestão, integrando o seu Conselho Diretor. Escreveu vários livros que se tornaram referência na área, entre eles Estrutura da Língua Portuguesa, lançado em 1970. Estudou com Roman Jakobson, nos Estados Unidos, sendo fortemente influenciado por esse linguista.
} 
superior (1972) e, para completar o ciclo, com o período da ditadura militar, iniciada em 1964.

A partir de então, o Estágio Supervisionado passa a ser uma disciplina da Grade Curricular de caráter obrigatório, porém chamado de Prática de Ensino. Considerado como importante e necessário para a complementação do processo ensinoaprendizagem do futuro professor, ele surge com objetivos pontuais, a saber: integrar o conhecimento adquirido pelo aluno em sala de aula à prática escolar, estimular o reconhecimento de habilidades e competências adquiridas em situações reais de vida e trabalho, instrumentalizar o aluno para a iniciação profissional, estando em sintonia com Projeto Pedagógico do Curso, objetivos da Instituição e com o perfil profissional docente desejado.

Em relação à formação docente, a Lei de Diretrizes e Bases da Educação Nacional LDB n 9394/96 reafirma a prática de ensino. Nesse documento, os estágios supervisionados constam como atividades de prática pré-profissional, exercidas em situações reais de trabalho, com ou sem vínculo empregatício. O estágio curricular, como procedimento didático-pedagógico, é uma atividade intrinsecamente articulada com as demais atividades acadêmicas. É um componente curricular obrigatório para todos os alunos das licenciaturas, observadas as disposições curriculares legais. Para cada aluno, é obrigatória a integralização de carga horária total do estágio e nela não se incluem as horas destinadas ao planejamento, orientação paralela e avaliação das atividades, em conformidade com as normas de um Manual de Estágio de cada instituição, devidamente aprovado pelos órgãos competentes e disponível a toda comunidade acadêmica.

A Lei de Diretrizes e Bases da Educação Nacional, mencionada, pela primeira vez na história da educação do País, na Constituição de 1934, teve por objetivo possibilitar aos sistemas de ensino a aplicação dos princípios educacionais constantes da Constituição Federal. A LDB é, portanto, uma lei que rege os Sistemas de Ensino e, sempre que uma nova Constituição é promulgada e redefine as bases da educação nacional, faz-se necessária a elaboração de uma nova LDB.

Por isso, com a promulgação da Constituição de 1988, tornaram-se obsoletas as leis de diretrizes e bases anteriores $(1961 ; 1968 ; 1971)$, pois a demanda de formação e escolaridade da população também ficaram diferentes. A partir desse fato, no mesmo ano de 1988, houve amplo e longo processo de debate em torno das prioridades educacionais a constarem em Lei, que acabou resultando na LDB 9394/96, promulgada pelo presidente da República em dezembro de 1996.

Os anos foram especificados para situar o leitor, mas é preciso considerar que o processo de disciplinarização não se restringe a um período de tempo com datas fechadas, pois o conhecimento se inscreve em um horizonte de retrospecção e também projeta um horizonte de projeção (AUROUX, 1992, p.11), nos efeitos de sentido dos saberes das ciências da linguagem. Desse modo, consideramos também as condições históricas que determinam a constituição do discurso a respeito do/sobre o sujeitoprofessor. 
Nos períodos citados, com o aceso à escola facilitado, a demanda de alunos existentes obriga o Estado contratar professores em grande escala, para darem conta de tal situação. Na lei da oferta e da procura, quem quisesse ser professor era contratado. Considerando a formação mínima dos candidatos, foi preciso "acompanhá-los" na prática que passam a exercer. Assim, pessoas com um pouco mais de formação são encarregadas de "acompanhar" os professores em atividade. Na própria Lei 5692/71, também está previsto, em caráter suplementar, várias possibilidades de suprir-se a falta do docente adequadamente formado. Mantêm-se em vigor os esquemas emergenciais de habilitação ao magistério, os chamados Esquemas I e II, que ofereceriam as disciplinas didáticas a profissionais liberais que intencionavam ingressar no magistério; por exemplo, um engenheiro agrônomo, ao passar pelo esquema I e II, tornar-se-ia professor da disciplina de química.

Nesse sentido, conforme Chervel (1990), o processo se configura e a disciplina de estágio obrigatório é implantada, naturalizando a necessidade de os estagiários serem observados in loco. Muitas turmas são abertas, materiais são organizados, teorias, didatizadas; tudo isso para dar conta das necessidades numéricas da educação no país. $\mathrm{Na}$ área da linguagem, havia a necessidade de se implantar mudanças no ensino de Língua Portuguesa, com o objetivo de produzir uma nova relação dos falantes com sua língua, formando outro tipo de leitor e de trabalhador, o que afeta também a formação do professor recrutado no período.

Muitas décadas se passaram, o acesso ao ensino superior aumentou consideravelmente, o nível de formação dos professores melhorou, projetos de formação continuada gratuita acenam, porém a prática de estágio supervisionado (obrigatório) naturalizada permanece até hoje, sem qualquer questionamento. Estamos na era da informação, do acesso à técnica, na era do conhecimento. Será mesmo indispensável essa obrigatoriedade, com o devido acompanhamento do professor titular da disciplina? São realmente essenciais as visitas do supervisor acadêmico in loco no período do estágio, a fim de validá-lo? De acordo com as leis que norteiam o ensino, sim.

Em relação à supervisão prevista nos estágios, além de regularizar, os documentos oficiais, lidos até a escrita deste texto, parecem apontar o intuito de, primeiramente, mostrar um comprometimento, por parte do governo, na superação dos problemas e dificuldades em termos educacionais no ensino; também explicitar sua principal finalidade, ou seja, apresentar as linhas norteadoras para a (re)orientação curricular, e mais, propor uma forma de didatizar as teorias educacionais circundantes, sendo ampliada para os demais cursos, a partir da Lei 11.788, de 25 de setembro de 2008 .

\section{3) Algumas discussões necessárias}

Diante das colocações feitas em relação à nomeação/designação, percebemos

que o nome "supervisionado" (co)responde a algo que vem antes, ligado ao discurso fundador de um imaginário social sobre a língua que a escola deve(ria) ensinar, naturalizado e colocado a efeito no exercício do estágio pelos acadêmicos, bem como 
nas leis e diretrizes que determinam o percurso da educação no país. Oficialmente, a única língua que faz sentido é a nacional padrão, considerada como um sistema objetivo, autônomo, fechado e significado em si mesmo, já definido por Saussure no Curso de Linguística Geral em 1916. No entanto, essa noção de língua geral, igual em/para todos deve ser revista, inclusive na perspectiva de Orlandi (2001, p.47), pois "para que a língua faça sentido, é preciso que a história intervenha, pelo equívoco, pela opacidade, pela espessura material do significante".

Como na língua nada é por acaso, a nomeação da disciplina como Estágio Supervisionado em Língua Portuguesa ${ }^{5}$, também não o é. Chamamos a atenção para o termo "Supervisionado", que, no constituir do nome da disciplina, poderia ser/ter sido outro, como por exemplo, orientação. Supervisionar carrega junto, em seu sentido, o dever, dever esse oferecido a alguém, de vigiar o estagiário que não é capaz de dar conta da tarefa, uma tarefa de ensinar, mesmo tendo passado quatro anos no meio acadêmico. Considerando, portanto, que essa é uma questão legal, assim permanece o estágio, sem ser questionado, intacto, aceito passivamente por todos envolvidos no processo: pais, alunos, professores, diretores das escolas e legisladores.

É preciso refletir sobre essa prática, iniciando pelo nome da mesma, pois Pêcheux (1993, p.16) explica que o "sentido de uma palavra, expressão, proposição, não existe em si mesmo (isto é, em sua relação transparente com a literalidade do significante), mas é determinado pelas posições ideológicas colocadas em jogo no processo-sócio-histórico em que palavras, expressões, proposições são produzidas".

Conforme Bittencourt (2003), na organização das disciplinas nas instituições há um embate entre o campo epistemológico e o cultural. É preciso conhecer a função, o papel que cada um dos envolvidos no processo pedagógico desempenha. Isso porque a imagem do sujeito-professor vai se constituindo paralelamente com o processo de institucionalização das disciplinas, em especial no Estágio Supervisionado, pois o nome em si já desloca para outros sentidos possíveis, dentre eles uma forma de controle, muito mais do que uma orientação. Apresenta alguém sem condições que, apesar da formação recebida na universidade, ainda no final do curso precisa ser fiscalizado.

Parece natural desconhecermos as questões que perpassam na implantação das disciplinas, já que são muito recentes as pesquisas desenvolvidas sobre a história das mesmas. Durante muito tempo, o efeito de evidência norteado pelo funcionamento ideológico nos fez acreditar que a escolha das disciplinas a comporem um Curso ${ }^{6}$, os conteúdos eleitos, bem como os recortes feitos nas mesmas era uma escolha do professor organizador, ou uma decisão do colegiado. No entanto, é preciso perceber esses recortes como processo histórico, que vem se constituindo, sendo inclusive norteador das práticas de ensino. O nome da disciplina Estágio Supervisionado em Língua Portuguesa não é uma decisão, uma escolha da qual o sujeito dá conta, pois há

\footnotetext{
${ }^{5}$ Mesmo que, em alguns artigos dos documentos oficiais analisados, a disciplina em estudo é chamada de prática de estágio, nas cinco instituições pesquisadas o nome da disciplina é "Estágio Curricular Supervisionado Obrigatório em/de Língua Portuguesa".

${ }^{6}$ Nesse trabalho tratamos especificamente das disciplinas que compõem o Curso de Letras.
} 
nessa nomeação algo muito maior. A nomeação é, por causa da predicação, um ato que diferencia, sendo também um ato que identifica.

Por isso, esses recortes quando significados vêm significar o imaginário dos componentes, já que ao significar, o sujeito(se) significa. Certamente, isso faz a diferença no processo de formação dos futuros professores, pois "a relação com a história mostra a eficácia do imaginário, capaz de determinar as transformações nas relações sociais e constituir práticas” (ORLANDI, 1994, p. 57).

\section{4) Alguns resultados}

Para discutir sobre o "Estágio Supervisionado em" é preciso considerar, sempre, as questões que envolvem a implantação e ou a retirada de determinadas disciplinas, pois, de forma geral, as mudanças que ocorrem são, na verdade, respostas dadas a determinados grupos.

Conforme levantamento feito, esse termo não aparece descrito dessa forma nos documentos oficiais, mas vai mudando a partir da sua implantação nas Instituições de Ensino Superior. Há uma incoerência, pois essa disciplina surge em um momento ditatorial, nomeada pela lei como "Prática de Ensino"; no entanto, apesar da autonomia oferecida às IES, esse processo provoca tantos deslocamentos de sentido, a ponto de ela ser nomeada Supervisão de Estágio até os dias atuais. Pelo funcionamento ideológico, esse sentido vai se modificando, pois aquilo que era para ser uma prática de ensino vai se constituindo como uma forma de controle. Quem é esse sujeito discursivizado nesses documentos? Afinal, que professor é esse que estamos formando, se ele precisa ser supervisionado? Não podemos ignorar a existência de um sujeito institucional presente nos mesmos, mas pensar que posição-sujeito assume esse sujeito institucional que, na materialidade, deixa à mostra também o que se quer, o que se espera e o que se pensa desse sujeito-professor, que precisa ser supervisionado, controlado/vigiado.

Quando se profere algo, isso não vem sozinho, isso vem carregado de um imaginário. Essa nomeação responde a uma memória coletiva, constituída na relação de poder entre quem ensina porque sabe e quem deve aprender, justamente porque não sabe. Para Orlandi (2007), não dá para considerar apenas uma correlação entre linguagem e sociedade. $O$ discurso deve ser definido como processo social cuja especificidade está em que sua materialidade é linguística. Há uma construção que é conjunta entre o social e o linguístico.

Nesse sentido, reportamo-nos também a Pêcheux (1993), em relação à ilusão que o sujeito tem de ser dono e ter controle do seu discurso. O imaginário, por sua vez, é constituído no processo de "interiorização da exterioridade". Nessa perspectiva, compreendemos que o que o sujeito pensa ou fala é a manifestação de uma objetividade subjetivada, ou, para usar os termos empregados por Courtine (1981, p. 50), de uma exterioridade interiorizada. Aquilo que um sujeito enuncia, "a sua fala", é produto da subjetividade, de uma subjetividade facultada, tornada possível e produzida pelo social.

Quando analisamos a forma como as Leis da esfera educacional se materializam, passamos a questionar sobre o que o professor realmente sabe sobre as 
finalidades do ensino. Ele é falado ali como um mero executor, que vai cumprir com as finalidades previstas para o ensino, mesmo que ele não tenha noção do que perpassa por essa regularização. Isso porque, teoricamente, as instituições recebem "carta branca" para regular as modalidades do ensino, mas vale ressaltar que essa liberdade pedagógica não é, ao nível dos indivíduos, mais do que meia-liberdade. E mais, o docente é quase um agente impotente de uma didática que lhe é imposta do exterior. Mesmo parecendo contraditório, isso tem sentido, pois há um fazer pedagógico escolar muito rotineiro, sem questionamentos, sem pesquisa, já previsto nas Leis, que regem o ensino no país. O professor não participa das discussões que envolvem as políticas públicas do país, apenas é chamado a colocá-las em prática; não fala, mas é falado; não propõe, mas é proposto e assim sucessivamente.

Nessa relação impositiva, parece que há algo naturalizado, numa adaptação para que aquilo proposto pela lei venha a funcionar. Temos de discutir sobre o que faz que uma disciplina funcione, quem a pensou dessa forma, quais seriam as exigências internas que constituem aparentemente o seu núcleo. Para Bittencourt (2003), as disciplinas carregam marcas, sejam aspectos teóricos do seu tempo, influência dos modos psicopedagógicos, ou da ideologia. Se percebermos isso, vamos entender que uma disciplina muda quando sua finalidade mudou, pois a sua prática não é aleatória, há exigências intrínsecas que podem ir se acomodando numa evolução gradual e contínua.

Pensar uma disciplina de estágio obrigatório, nomeado de Supervisionado, é perceber que há um corte estreito entre a instrução, considerada como conteúdo, e a pedagogia, que seria a forma de transmissão desse conteúdo. Por isso, é preciso aprender a ensinar, pois é muito perigoso tornar a escola um laboratório dos aprendentes. Ou seja, não adianta eleger disciplinas, conteúdos a serem ensinados, se há uma inércia escolar instalada na questão pedagógica.

Questionamos a disciplina de estágio para refletir sobre o conflito existente na distribuição das disciplinas escolares, novamente retomando a questão das suas finalidades, e que elas são um dos elementos motores da escolarização. Com base em Chervel (1990, p. 184), é muito sério afirmar que a instituição de uma disciplina serve para que ocorra o processo de aculturação dos alunos em conformidade com a sua gênese, constituída em sua razão social. A partir de sua implantação, será selecionado o que será ensinado, mas não há como realmente mesurar o que será aprendido.

Nesse sentido, Scherer e Brum de Paula (2002, p. 125) apontam que a história de uma disciplina tem sua origem, de um lado, na história das ideias e, de outro, na história das instituições que ajudaram a constituí-la. Importante a destacar nesse percurso é o modo como uma disciplina se estabelece no contexto universitário, a partir de materiais que são significativos na dimensão de sua difusão. Estudar a história das disciplinas é, por isso, entender que elas são constituídas a partir de finalidades religiosas, sócio-políticas, psicológicas e culturais, atravessadas por questões ideológicas.

O processo de institucionalização de uma disciplina que parece legitimada apenas pelo professor perpassa por uma política de Estado, o qual pode exercer seu poder coercitivo, fazendo com que se inscrevam, na memória do discurso, as 
prioridades na formação de sujeitos-professores. Na visão de Althusser (1985), a escola representa o mais forte e eficiente aparelho ideológico do Estado (o aparelho ideológico de Estado dominante).

\section{Considerações finais}

Chamamos a atenção para o fato de que a história da língua portuguesa é uma história escrita, para ser lembrada e ensinada, na qual há um modo de dizer sobre a língua e sobre a nação (ORLANDI, 2001, p.47). Desconfiamos de uma disciplina que tem por função supervisionar o sujeito professor na sua prática de estágio levada a efeito, pois há nisso uma relação de controle, de poder e de punição, cuja pena é a reprovação para aqueles que não conseguem ensinar a língua nacional, como única, perfeita e autônoma.

Enfim, para entender a organização escolar hoje, é preciso conhecer a sua constituição numa perspectiva histórica. Dessa forma, será possível entender também que a organização escolar, dividida em departamentos, séries, disciplinas, horários e espaços não é uma escolha do professor, mas resultado de fatores pautados em intenções não casuais, planejadas de acordo com o interesse de alguns. É o estatuto institucional que sustenta a posição ocupada pela disciplina "Estágio Supervisionado em Língua Portuguesa", enquanto questão legal, mas sua permanência é efetivada pela noção de língua e de sujeito que possuímos.

Chervel (1990, p. 185) afirma que as disciplinas não podem ser entendidas como metodologias e que a história das mesmas deve ser analisada sob três aspectos: a gênese (de onde), os objetivos (para quê) e o funcionamento (como). Talvez se estudássemos mais sobre isso, conseguiríamos entender as chamadas matérias-mães, bem como o desaparecimento de algumas disciplinas, sendo que umas voltam e outras não. Inclusive, há disciplinas que duram para sempre, sem serem questionadas, dentre elas, o "Estágio Supervisionado nas Licenciaturas".

Nesse percurso teórico, talvez sejam encontradas algumas respostas nesses efeitos de sentidos ali constituídos, pois a materialidade mostra que a imagem projetada do sujeito-professor está relacionada com as questões histórias, políticas e sociais, as quais orientam os documentos oficiais, norteadores do ensino de língua no Brasil. Para Orlandi (2007, p. 143), o sentido é uma relação determinada do sujeito com a história, um sujeito de linguagem, que não é mestre de si mesmo, nem é capaz de dominar e controlar uma linguagem que não é aparente.

Considerando que o discurso é "o efeito de sentidos entre interlocutores" (PÊCHEUX, 1995, p. 160), o discurso sobre a/da imagem do sujeito professor que se quer/acredita formar está materializado na nomeação da disciplina "Estágio Curricular Supervisionado Obrigatório em Língua Portuguesa", a qual movimenta efeitos de sentidos diversos, que acenam para uma questão de controle, vigilância e punição, que vão além da orientação de uma prática, apresentada na evidência, pois "os dizeres não são, como dissemos, apenas mensagens decodificadas. São efeitos de sentidos que são produzidos em condições determinadas" (ORLANDI, 2007, p. 30). 
Entre supervisionar e orientar há grandes diferenças, há também a constituição e permanência de uma disciplina que ocupa um lugar de destaque nos Cursos de Letras do país, há o ideológico funcionando, que movimenta os efeitos de sentido, bem como mostra os efeitos de evidências, aos quais buscamos compreender. Diante dessas considerações, os significados encontrados no dicionário sugerem que estagiar é tarefa do aluno, futuro professor, aquele que precisa ser vigiado; supervisionar é incumbência da universidade, representada pelo professor, que tem a função de inspecionar, definido no Larousse (2000) como vigiar.

\section{Referências}

ALTHUSSER, L. Aparelhos ideológicos de Estado. 10. ed. Rio de Janeiro: Graal, 1985.

AUROUX, S. A revolução tecnológica da gramatização. Campinas (SP): UNICAMP, 1992.

BIACHI, A. C. M; ALVARENGA, M.; BIANCHI, R. Manual de Orientação: estágio supervisionado. São Paulo: Pioneira Thomson Learnig, 2002.

BITTENCOURT, C. M. F. Disciplinas escolares: história e pesquisa. In: Histórias das disciplinas escolares no Brasil: contribuições para o debate. Organizado por Marcus Oliveira e Sirlei Maria Fischer. Bragança Paulista: CDAPH, 2003.

CHERVEL, A. História das disciplinas escolares: reflexões sobre um campo de pesquisa. In: Teoria \& Educação. Porto Alegre: Pannonica. p.177-229, 1990.

COURTINE, J. J; MARANDIN, J. M. Quel objet pour l'analyse de discours? In: Matérialités discursives: Actes Du Colloque, avril, 1980, Paris X. Nanterre Lille: Presses universitaires de Lille, 1981.

GUIMARÃES, E. Designação e espaço de enunciação: um encontro político no cotidiano. In revista LETRAS, UFSM, n. 26, p. 53-63, jan./jun, 2003.

INDURSKY, F. Lula lá: estrutura e acontecimento. In: Organon: Revista do Instituto de Letras da UFRGS, Porto Alegre, v. 17, n. 35, 2003.

LAROUSSE. Dicionário da Língua Portuguesa. São Paulo: Editora Nova Cultural, 2000 .

ORLANDI, E. P. O Lugar das Sistematicidades Linguísticas na Análise de Discurso. In: Delta, v.10, n.2, SP, Educ, 1994. 
E; GUIMARÃES, E. História das Ideias Linguísticas. São Paulo: PontesUNEMAT, 2001.

Análise de Discurso: princípios e procedimentos. Campinas, SP: Pontes, 2007.

PÊCHEUX M. O discurso: estrutura ou acontecimento. 4 ed. Tradução Eni P. Orlandi. Campinas: Pontes, 1993.

[1975] Semântica e Discurso - uma crítica à afirmação do óbvio. 2a edição, Campinas: Editora da Unicamp, 1995.

[1983] Semântica e discurso: uma crítica à afirmação do óbvio. 2. ed. Campinas: Pontes, 2009.

PLATÃO. Diálogos. Teeteto - Crátilo. 3. ed. Belém:UFPA, 2001.

SCHERER, A. E; BRUM DE PAULA, M. R. Memória e história das ideias: o ensino do francês no RS do fim do século XIX ao início do século XX. In: ORLANDI, E. P.; GUIMARÃES, E.(Orgs.). Institucionalização dos estudos da linguagem disciplinarização das ideias linguísticas. Pontes: Coll. História das Ideias Linguísticas, 2002.

SCHERER, A. E. Linguística no sul: estudo das ideias e organização da memória. In: BRUM DE PAUlA, M. R.; GUIMARÃES, E. (Orgs.). Sentido e Memória. Campinas, Pontes Editora, PROCAD/CAPES, 2005.

SILVA, M. V. História da alfabetização no Brasil: a constituição de sentidos e do sujeito da escolarização. Tese (Doutorado em Linguística). Campinas: IEL/UNICAMP, 1998. 